\title{
EL ESPÍRITU DEL GRANO: TRADICIONES AGRÍCOLAS PROPICIATORIAS EN GALICIA Y EN OTRAS COMUNIDADES EUROPEAS
}

\author{
por \\ FERNANDO ALONSO ROMERO
}

En 1953 Bouza Brey publicó un artículo en la "Revista de Dialectología y Tradiciones Populares", sobre los ritos agrarios propiciatorios del espíritu de la tierra. En él mostraba un interesante campo de investigación y planteaba varias incógnitas (Bouza Brey, F. 1953). Para realizar su trabajo había partido del estudio de una costumbre agrícola, denomianda canto do grilo, que se celebraba en el municipio de Cortegada do Miño (Ourense) a finales del mes de abril, cuando se terminaba el proceso de la endeita o laboiro, es decir, la cava del maíz: Entonces, al terminar, por el anochecer, se juntan los hombres y hacen un a modo de pedestal ("estada") con las "eixadas", colocando cuatro hincadas, con los hierros hacia arriba. Súbese uno de los obreros al pedestal formado por los instrumentos de labranza, coloca sobre su cabeza la calabaza con el vino y da comienzo con un estentóreo "iIjujúuu!, mientras los demás forman corro y corean la canción que el de la calabaza inicia...

¡Grilo, meu grilo...! (Bouza Brey, 1953, 69).

Bouza Brey recogió diversas variantes de esta canción, pero todas comienzan por el mismo verso pentasílabo en el que se invoca al grillo:

¡Grilo, meu grilo

da Ponte do liño,

o viño na cuba

non sementa o millo!

"CUADERNOS DE ESTUdIOS GALLEGOS", Tomo XLI, Fascículo 106, Santiago 1993-94. 


\author{
;Grilo, meu grilo \\ da Ponte-Castelo, \\ matache o teu pai \\ e non che teño medo! (Bouza Brey, 1953, 69).
}

Durante el transcurso de la cava, cuando los hombres encontraban un grillo común, intentaban echárselo a las piernas de alguna de las mozas que trabajaban con ellos. Al grillo se dirigían todas las imprecaciones y los desafíos; se simulaba incluso que se afilaban los instrumentos como si fueran a matarlo, mientras que, con frecuencia, en medio de las cantigas se lanzaban gritos de alabanza al dueño de las tierras, el cual tenía al final la obligación de obsequiar a todos con una merienda. Según Bouza Brey, de esta costumbre se desprende que el espíritu de la vegetación en Galicia, al menos en su parte meridional, estaba representado por un insecto, el grillo campestre. Mientras que en el Bierzo el espíritu vegetativo, como lo llamaba Bouza Brey, se encarnaba en un vegetal (Bouza Brey, 1953, 78, 79).

En Galicia se dice que es pecado matar un grillo (Risco, V. 1947, 378), y que su canto es signo de bienestar (Rodríguez González, E. 1960). Esta es una creencia muy común por toda Europa. En Portugal suelen tenerlo, al igual que en Galicia, en las cocinas de las casas, pues se cree que su canto trae felicidad y fortuna (Dos Santos Júnior, J.R. 1964, 375). A los campesinos de la región francesa de Limousin les gusta oir el canto del grillo ante el fuego de sus hogares; imaginan que les trae buena suerte (Devlin, J. 1987, 96). A finales del siglo XIX, Lady Wilde recogió en Irlanda la creencia de que los grillos eran animales encantados. En general, a los campesinos irlandeses no les gustaba hablar del grillo. Cuando lo hacían, se expresaban con vacilación y respeto, como si le temieran. Sin embargo, no estaba en absoluto considerado como un insecto dañino; muy al contrario, su presencia en la cocina de la casa era señal de buena suerte. Se decía también que su canto nocturno espantaba a las hadas maléficas y que podía vivir cientos de años (Wilde, L. 1971, 178).

El hecho de que en Galicia se respete al grillo contrasta con el comportamiento que tenían los campesinos con él cuando lo encontraban durante la labranza. Ya Bouza Brey se había dado cuenta del significado enigmático que tenía una de las coplas del canto do grilo; concretamente la que decía:

¡Grilo, meu grilo

da Ponte-Castelo,

"CUADERNOS DE ESTUDIOS GALLEGOS", Tomo XLI, Fascículo 106, Santiago 1993-94. 
matache o teu pai

e non che teño medo!

Esta cantiga sólo tiene sentido si admitimos la suposición de Bouza Brey: el grillo representa al espíritu del grano que debe morir para que el campo vuelva a dar sus frutos. Es muy difícil ahondar en los remotos orígenes de estas creencias. El paso del tiempo las ha ido transformando tanto que los elementos de análisis originales con los que contamos son muy débiles. La letra de esta cantiga es muy probable que se cambiara también, y que su único nexo con la composición primitiva sea la figura del grillo. Hay que tener en cuenta que nos estamos refiriendo a tradiciones agrícolas indoeuropeas, con paralelos en varios países, cuyos elementos de relación directa son dudosos en un contexto cultural sincrónico, aunque se hace evidente la existencia de un tronco común del que derivaron. Así, por ejempo, en algunas leyendas irlandesas relacionadas con la siega, se mencionan también insectos de color negro, escarabajos y tijeretas que se ocultan en el mango de las hoces y que confieren a los segadores una enorme habilidad y rapidez durante las faenas de la siega. Estos pequeños insectos estaban relacionados en Irlanda con una divinidad de la naturaleza, cuya figura fue analizada en profundidad por varios autores (O'Crualaoich, G. 1988, 156). De ahí, pues, las facultades mágicas que infundían a sus poseedores, y que éstas se desvanecieran cuando alguien los mataba. Del suroeste de Irlanda procede uno de los mitos que más información ha suministrado a este tema. Allí estaba el territorio de la Vieja de Beare, poderosa mujer que vencía a todos los segadores a los que incitaba para que compitieran con ella en las faenas de la siega. Pero se quedó sin fuerzas cuando un día le mataron al escarabajo que llevaba oculto en el mango de su hoz.

En Galicia tuvo que existir en una época remota alguna creencia que vinculó también al grillo con alguna divinidad agraria, que fue la responsable del comportamiento enigmático de los segadores gallegos cuando se encontraban con él. Para profundizar en esta suposición, vamos a mostrar más elementos de análisis.

Relata Bouza Brey que cuando, al estar la cuadrilla de operarios cavando la tierra, pasa por sitio próximo una persona, se la llama hasta que conteste, y al hacerlo ella, todos los presentes baten con una piedra en la parte férrea de los instrumentos agrícolas ("eixada" = azada), que colocan hacia arriba al tiempo que exclaman de modo estentóreo, con ligera melopea:

"CUADERNOS DE ESTUDIOS GALLEGOS", Tomo XLI, Fascículo 106, Santiago 1993-94. 


\section{¡Porra pra ti; \\ pra ti porra sí!}

continuando de esta suerte la algazara hasta que desaparece el chasqueado de la vista de los trabajadores, o se aleja de la heredad en que hacen su labor (Bouza Brey, 1953, 72). Este autor señala la semejanza de este rito con otro que se realiza en Mecklemburgo (Alemania); allí los trabajadores del campo también producían un gran barullo y afilaban las guadañas como si fueran a matar al extraño que casualmente pasaba por delante del campo $(1953,72)$. Mannhardt menciona varios testimonios de estas simuladas amenazas de muerte que se efectuaban durante la siega en diferentes países europeos. Pero a principios del siglo XX esas actitudes eran ya simples juegos o tradiciones inocentes. Quedaba muy lejos la época de los ritos cruentos en los que se habían gestado, aunque pervivían todavía algunos de sus rasgos más significativos (Mannhardt, W. 1884, 39).

Bouza Brey veía en esas costumbres de la siega la existencia velada de antiguos cultos a un espíritu de la tierra. Sin embargo, no efectuó en su estudio ningún análisis interpretativo de la costumbre de aporrear al intruso que pasaba por delante del campo en el que estaban faenando. La explicación del comportamiento agresivo que mostraban los campesinos contra cualquier extraño que interrumpía la labranza o la siega, la había dado Frazer a principios de siglo en su genial obra The Spirits of the Corn and of the Wild. Frazer efectuó su estudio interpretativo partiendo de la leyenda de Lityerses. Para Frazer los orígenes remotos de ese comportamiento hay que buscarlos en los ritos y cánticos lastimeros que entonaban los egipcios cuando segaban la primera gavilla de trigo en la que suponían que se refugiaba el espíritu del grano, representado por Osiris, que moría al ser cortado por la hoz (Frazer, J.G., 1966, 215). Tonadas quejumbrosas parecidas cantaban los segadores de Fenicia y de otras partes de Asia Menor. Es probable que todas estas cantinelas doloridas fueran lamentaciones de los segadores por matar con sus hoces al dios del grano (Frazer, J.C., 1956, 428). Los segadores frigios cantaban una canción llamada Litierse en la que se ensalzaba la habilidad de Lityerses. según la leyenda, Lityerses era hijo de Midas, rey de Frigia, y se había hecho famoso por su habilidad en la siega. A todos los extraños que pasaban por sus campos los obligaba a segar con él. Después los ataba a una gavilla y les cortaba la cabeza con la hoz. Hasta que un día llegó Hércules y mató a Lityerses de la misma forma, acabando así con su cruel proceder. Los frigios, según Frazer, consideraban que cualquier persona que pasara por delante de sus campos 
durante la siega, era la personificación del espíritu del grano; por eso los segadores la cogían, la ataban a una gavilla y la decapitaban. Su suposición la fundamenta en los paralelos que ve en las costumbres europeas que se efectuaban durante la siega, así como también en los sacrificios que, en general, celebraban todos los pueblos primitivos para estimular la fertilidad de los campos (Frazer, 1966, 215 y ss.).

Veíamos antes que en el folklore irlandés, así como en su antigua literatura, aparece la figura de una vieja, o bruja, la llamada Cailleach Bearra, la Vieja de Beare, en la cual se observan los atributos propios de una diosa de la naturaleza. De ella se dice que enseñó a su pueblo a trillar de un modo diferente al tradicional. Aconsejaba el empleo de madera de acebo en los mangos de los mayales y de avellano en sus pértigas. También cuentan los relatos que era dueña de un gran campo de trigo y que desafiaba a todo aquel que pasaba por delante, forzándolo a participar en la siega. Pero como nadie lograba vencer su habilidad y rapidez como segadora, la Vieja les cortaba a todos las piernas con su hoz. Hasta que un día llegó un astuto segador, y descubrió que su poder radicaba en las virtudes mágicas que le confería un escarabajo negro que la mujer ocultaba en el mango de la hoz. El segador lo mató, y al instante la anciana perdió todas sus fuerzas, siendo incapaz de concluir la siega (Ohógáin, D., 1990, 68). Una variante de esta leyenda aparece en el cuento popular irlandés La tijereta de la hoz, que narra la vida de un segador capaz de segar a gran velocidad gracias a una hoz que le había regalado un amigo. Un día se dio cuenta de que el mango de la hoz estaba flojo. Al disponerse a arreglarlo, salió de él una tijereta negra que se escapó. Cuando se reincorporó a la faena de la siega, descubrió asombrado que la hoz ya no segaba tan maravillosamente como antes, circunstancia que atribuyó al poder mágico que le infundía el repulsivo insecto que habitaba en ella (O'Sullivan, O., 1977, 85). Relacionado también con estos relatos, está el mito celta irlandés que nos describe cómo la diosa Ana (Anie) fue vencida por el dios Lug mientras ambas divinidades rivalizaban para averiguar quién era más rápida segando (Davidson, H.E., 1993, 112). No cabe duda de que el origen de estos relatos irlandeses partió del mismo tronco común que la leyenda de Lityerses. De ella debió de salir también o canto do grilo de Cortegada do Miño, último vestigio de un relato más amplio en el que se describía alguna historia parecida a la de la Vieja de Beare que mataba a los segadores. Naturalmente, esto último es sólo una suposición que requeriría un estudio comparativo más detenido.

La figura de la Vieja de Beade es muy compleja, pues en las descrip-

"CUADERNOS DE ESTUDIOS GALLEGOS", Tomo XLI, Fascículo 106, Santiago 1993-94. 
ciones en las que aparece se la describe con diferentes personalidades y en distintos contextos. Sintetizando, se puede decir que su origen lo determinó la creencia indoeuropea en alguna diosa Madre, cuyos rasgos se advierten también en otros personajes femeninos de los mitos celtas irlandeses. En el folklore moderno de Irlanda y de Escocia, la Vieja de Beare es un personaje femenino con connotaciones violentas y desagradables. En el folklore escocés está relacionada con las fuerzas de la naturaleza, especialmente las tormentas y las tempestades en el mar. Y es también la diosa protectora de los ciervos. Su residencia puede estar en lo alto de una montaña, en un páramo desierto, en un acantilado o en un desolado islote desde el que controla las olas del mar. En el folklore noruego se dice que la Vieja de Beare procede de Noruega, y que desde ese país transportó por el aire grandes piedras y rocas con las que formó las montañas, las costas y las islas de Escocia. Mientras que en el folclore irlandés a la Vieja se la relaciona principalmente con la península de Beare, en el suroeste de la isla, aunque por toda Irlanda hay leyendas sobre dólmenes y megalitos que construyó la Vieja con las rocas que transportaba en su delantal. Krappe opina que la Vieja es una antigua diosa agraria anterior a la civilización céltica, y también una diosa de ultratumba, semejante a la Demeter griega, diosa de la fertilidad y de la muerta (Krappe, A.H., 1936, 302). O Crualaoich descubre en ella tres rasgos principales de su personalidad:

1) Mujer vieja y bruja, como aparece en los relatos populares del suroeste de Munster (Irlanda).

2) Creadora del entorno geográfico de un determinado territorio.

3) Diosa de los cereales. Como tal aparece en contextos agrícolas: la siembra, la siega y la trilla. Enseñando a los agricultores o desafiando a los segadores a participar en un concurso de siega. Los relatos de este tipo se conservan sobre todo en el este de Galway y en Clare (Irlanda) (O Crualaoich, G., 1988, 172).

Frazer, al comparar la leyenda de Lityerses con las tradiciones agrícolas del norte de Europa, advertía en ellas dos aspectos importantes:

1) Un comportamiento desafiante en el proceso de la siega.

2) Un trato muy peculiar con los intrusos.

En las Islas Británicas era tradicional que los segadores porfiaran entre ellos para ver quién era más hábil cortando la última gavilla. En Gommern, cerca de Magdeburgo (Alemania), al segador que cortaba la última gavilla lo cubrían completamente con pajas y lo ataban. Después lo paseaban por todo el campo en medio de las burlas de los segadores. En Baviera esta costumbre se denominaba coger al Viejo o matar al Viejo; nombre que se 
utilizaba también en otras zonas de Europa para referirse a la última gavilla en la que suponían que se ocultaba el espíritu del grano (Frazer, 1966, 221). En Portugal vestían de viejo a la última gavilla y corrían con ella por los campos (Braga, T., 1985, I, 121). También en Alemania existía la costumbre de apresar a cualquiera que pasara por delante de un campo en el que se estaba segando. Lo tradicional era atarlo con pajas y no dejarlo escapar hasta que aceptaba pagar un rescate (Mannhardt, W., 1884, 35). Esta misma práctica se seguía en Noruega y en Francia. En Escocia, además de atar al extraño, lo zarandeaban y lo dejaban caer violentamente contra el suelo (Frazer, 1966, 222). Algo parecido sucedía en Galicia cuando se celebraba el rito del mazacuco al terminar de arar un campo. Los labradores cogían a un compañero, o compañera, por los brazos y los pies y lo balanceaban de un lado a otro sobre'el arado, dejando finalmente que se golpeara contra el suelo (y le daban con o cu no chao) (Lisón Tolosana, 1979, 137). También en Barroso (Portugal), cuenta Dos Santos Junior, los segadores cogían al dueño de los campos de centeno y lo manteaban, dejando a veces que su cuerpo tocara con el suelo. Después, acompañado de un cortejo fúnebre simulado, lo llevaban hasta su casa y allí lo dejaban en paz a cambio de un agasajo que debía ofrecer a todos (Dos Santos Junior, J.R., 1963, 60).

Durante el trabajo de la trilla, en algunos lugares de Galicia era costumbre que el que deshiciera el último haz de centeno se quedara con la grañeira, o atadera. Al terminar, iban todos los segadores a la casa de la dueña de las tierras para atarla con la grañeira y pedirle una merienda festiva, en la que se comían mexudas. Solamente tenían derecho a ella si lograban prender a la dueña. Llamaban mexudas a ciertas rodajas de pan de trigo rebozadas con huevo y fritas, las que después rocian con azúcar y canela o envuelven en miel. Si encuentran a el ama, da, además, de las mexudas, convite, que consiste en un cunco grande lleno de vino mezclado con miel y pan (Tenorio, N., 1982, 42).

En Cornualles a la última gavilla la llamaban the Neck (el Cuello). Después de cortarla, los segadores hacían con ella una muñeca de paja y la colocaban sobre la chimenea de la dueña de la granja, la cual tenía la obligación de invitar a todos a una cena abundante; en ella se solían cantar coplas alusivas a la fiesta tradicional de la siega (Deane, T. et al. 1975, 183). En el condado de Devon, colindante con Cornualles, también llamaban the Neck a la última gavilla. Solía cortarla el segador más viejo, rodeado de sus compañeros que gritaban de un modo armonioso y prolongado: ¡el Cuellooo...!, mientras la levantaban para que la vieran todos los 
presentes. Según un testigo que describió esta ceremonia a principios del siglo XIX, la "proclamación del cuello" producía a distancia un efecto maravilloso, más bello que el del almuecín turco que lord Byron tanto elogia y que prefiere al de todas las campanas de la Cristiandad (Frazer, 1956, 507). En otras zonas de las Islas Británicas al terminar la siega se hacía una muñeca con la última gavilla, y la colocaban en un carro encima de toda la cosecha. Los segadores también solían subirse al carro e iban gritando, tocando cuernos o cantando las canciones típicas de esa fiesta. Pero todas estas celebraciones ya han desaparecido. Sin embargo, en algunas granjas británicas aún se sigue festejando la terminación de la siega con una Harvest Supper, una abundante cena de la cosecha que se da a los segadores, aunque en un ambiente más íntimo y menos festivo que en otros tiempo (Hole, C. 1979, 138).

En el norte de Portugal el espíritu del grano lo representaba la anha, que era una piel de oveja que escondían los campesinos entre las pajas. Cuando la encontraban, se reunían todos en torno a ella y entonaban $o$ meio d'eira, un canto lúgubre con el que fingían que lamentaban la muerte de la anha. Sus voces sonaban extrañas por entre las quebradas, mezclándose a veces con otras que en la lejanía de otros campos cantaban también la misma canción:

Quem no meio da eira não bebe,

Palha e colmo se lhe perde

Mas se nos der bem de beber,

Palha e colmo (não) se lh'á-de perder.

Nossa ama perdeu as chabes

Na margem do çabolinho,

Nossa Sehhora as depare,

Siquer as chabes do binho.

Comadres, minhas amigas

Folgai todas que cá benho,

Morreu o nosso compradre,

Digan todos a de bem. (Veiga de Oliveira, et al. 1983, 48).

Cuando terminaban la faena agarraban al dueño de las tierras y lo llevaban hasta su casa fingiendo que estaba muerto. Una vez en ella, el dueño se liberaba de sus raptores e invitaba a todos a un vino. Por la noche se realizaba la quema solemne de la anha, y se enterraban sus restos en el campo mezclados con paja (Veiga de Oliveira, 1983, 43-50). En Celorico de Basto (Portugal) la anha era simplemente un manojo de paja que des-

"CUADERNOS DE ESTUDIOS GALLEGOS", Tomo XLI, Fascículo 106, Santiago 1993-94. 
pués de quedar reducido a cenizas, se enterraba en el campo que iba a fecundar. A continuación, los campesinos solemnemente volvían todos a cantar o meio d'eira,que já tinham cantado no "enterro do patrao", ao meio día. Na noite oscura, alumiados por lampiões e lumieiras, aquele grupo de homens a entoar com voz lúgubre um cântico arrastrado e plangente tomava, por vezes, um ar sinistro (Dias, J., 1951, 11). En Dinamarca cuando se terminaba la cosecha, una de las segadoras tenía que bailar con un maniquí hecho con las últimas espigas, y fingir que lloraba al considerarse "viuda" por la desaparición de su "marido", un ser mítico destinado a la muerte (Eliade, M., 1974, II, 118). También en Portugal, en la comarca del Tamega superior, se llevaba engañado al dueño de los trigales y lo sentaban en las gavillas. De allí no lo dejaban marchar hasta que accedía a invitar a una merienda (Taboada, J., 1965, 108). La llamada prisão do patrão era una práctica bastante corriente en el norte de ese país, con paralelos muy parecidos en otras comarcas europeas. Su origen está en los viejos ritos relacionados con la fertilidad de la tierra y la buena germinación de la simiente (Dos Santos Junior, J.R., 1977, 154).

De todo esto se deduce, que aunque en los últimos siglos los segadores ya no cortaban la cabeza de los extraños, sin embargo, se advierte por los gestos y el comportamiento que mantenían con ellos, que pervivía todavía la violencia del antiguo rito que se efectuaba para que la tierra fuera fértil. Se creía que el extraño que pasaba por delante de los campos durante las faenas de la siega, podía ser la reencarnación del espíritu de la vegetación, que de ese modo intentaba escapar de la muerte ritual que le estaba reservada (Frazer, 1966, 253). No es fácil admitir que se conservaran a lo largo de los siglos una serie de "supervivencias", de manifestaciones relacionadas con los cultos a la fertilidad de los campos, pero, como bien dice Mingote Calderón, el ámbito en el que se mueven es el mismo: la cosecha. Desde este punto de vista es posible entender la permanencia formal a través del tiempo de una serie de manifestaciones similares que de otro modo supondrían una casualidad mayúscula el que se encontraran juntas $(1988,128)$. Mircea Eliade ve como muy probable el hecho de que todas esas ceremonias agrícolas se difundieran por el mundo a partir de ciertos centros (Egipto, Siria, Mesopotamia) y que muchos pueblos no asimilaran más que fragmentos de los conjuntos originarios (Eliade, M., 1974, II, 121).

También debemos tener presente que el folklore relacionado con la trilla, que en muchos aspectos coincide con el de la siega, puede ser anterior al empleo de determinados aperos utilizados en dicha faena. Veíamos 
más arriba que en el folklore irlandés se dice que la Vieja de Beare enseñó a los campesinos a trillar de un modo diferente. Esta circunstancia dificulta el problema de los orígenes de las costumbres que estamos analizando, pues podríamos pensar que con la llegada de nuevos instrumentos de labranza vino también ese folklore. Por ejemplo, en la Galia, en la zona comprendida entre el Rhin y el Mosela, el mayal se utilizó por primera vez en el siglo III d. de C., extendiéndose después por toda Europa. Los romanos utilizaban sencillos palos, o bastones simples sin articular (Mingote Calderón, J.L., 1988, 95). Pero esto no significa que fueran los pueblos germanos los que difundieron por todo el occidente europeo las creencias que estamos viendo, pues las actividades con las que estaban relacionadas se venían efectuando desde muy atrás.

Cuando Bouza Brey publicó a principios de los años cincuenta su interesante estudio sobre el espíritu de la tierra en Galicia, se celebraba aún en la provincia de Orense un rito propio de la recolección que tenía varios paralelos en otras comarcas campesinas de Europa. Sin embargo, Bouza Brey, como el mismo confiesa, no lo conocía. Dicho rito, en palabras del propio Bouza Brey, derivaba de la creencia de que en el último haz de la cosecha se refugiaba, después de saltar huido de uno en otro, el espiritu vivificador de las cosechas y que, por tanto, era necesario adueñarse de él para asegurarse éstas. ;Al menos nosotros no conocemos tal ritualidad! (Bouza Brey, 1953, 48). El gran etnógrafo asturiano Constantino Cabal recogió este testimonio de Bouza Brey y agregó que tampoco en Asturias se había logrado aún encontrar dicha creencia: En Asturias, por lo menos, aún nadie ha logrado hallarla, y en Galicia, por lo menos, Bouza Brey testifica que tampoco se la ha descubierto aún (Cabal, C. 1958, 48). Pero, a pesar de estas opiniones, en Galicia sí existía esa creencia. Es una lástima que Bouza Brey no llegara a conocer el rito que aún efectuaban los segadores de Santa Marta de Moreiras, en la provincia de Orense, cuando realizó su investigación, pues le hubiese gustado ver confirmada en la realidad de su propia tierra, sus sospechas de que también en Galicia se celebraban prácticas semejantes a las que él había visto en el Pirineo (Bouza Brey, 1953, 79) y que eran comunes en otras zonas de Europa.

En el año 1968, Xosé Ramón Fernández Oxea publicaba, con varios años de retraso, su preciosa monografía sobre Santa Marta de Moreiras (1925-1935). En este libro se cuenta que antes de concluir la siega del trigo, se reunían todos los segadores en torno a la última gavilla que faltaba por cortar. La denominaban o cabalo, o cabaliño, y le cantaban una cántiga, llamada o canto do cabalo que decía así: 


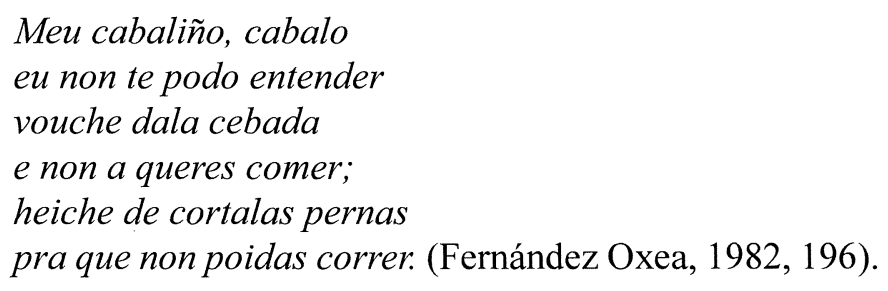

En otros lugares, también de la provincia de Orense, se cantaba la siguiente variante:

Iste é o canto do cabalo o canto do cabaliño.

Iste é o canto do cabalo:

¡éncheme a cunca de viño!

Arréame ben a fouce nos rebos do teu balado, que vimos a mocedade curtarlle os pes ó cabalo.

Magarcela, Magarcela Magarcela é boa herba.

Heiche de curtalas pernas, meu cabaliño redondo, heiche de curtalas pernas anque sea polo fondo.

Heiche de curtalas pernas, as pernas che hei de curtar, heiche de curtalas pernas pra que non poidas andar.

Magarcela, Magarcela, Magarcela é boa herba.

Heiche de curtalas pernas meu cabaliño, cabalo, heiche de curtalas pernas. ¡Adiós, adiós, deica outro ano! 
Después de cantar estas cantigas, corrían todos hacia la gavilla para ver quién era el primero que conseguía cortarla. Luego la colocaban encima del almiar (Fernández Oxea, 1982, 196-197). En la parroquia de Loureses (Orense), la última gavilla tenía que cortarla el dueño del terreno o una hija suya. Esta función se denominaba facer unha aña. Según el antropólogo Mandianes Castro, se trataba de una representación simbólica de la fertilidad $(1984,33)$. En varias aldeas del norte de Portugal se denominaba facer a anha a la acción de ocultar una gavilla de paja de centeno durante la trilla. Cuando los campesinos la encontraban, se celebraba el final de las tareas con una fiesta (Conde d'Aurora, 1966, 44). Es evidente, que en la figura de la anha, u oveja, se manifestaba la continuidad de viejas creencias relacionadas con el espíritu del grano responsable de la fertilidad de los campos. Con el corte de la gavilla, se simbolizaba el sacrificio de un animal en el que se encarnaba ese espíritu. Su entierro en el campo garantizaba su pervivencia en el renacer de los cultivos al año siguiente.

Llama la atención en el canto do cabalo de Santa Marta de Moreiras, la existencia de unos versos de alabanza a la magarcela que, aparentemente, no tienen relación con el tema de la siega ritual de la gavilla. Pero una visión detenida de las creencias relacionadas con esa planta, nos introducen aún más en el sorprendente mundo simbólico de los antiguos ritos de fecundidad. La magarcela es la manzanilla común (Matricaria chamomilla). Su nombre latino se origina de matrix, la matriz, porque se considera que esta planta es buena para este órgano. En vasco se denomina amasabel bedarr, hierba de la matriz. Se suele criar entre las mieses, los barbechos, los terrenos ásperos, etc. Según Dioscórides, esta planta es buena para provocar el menstruo y el parto. En gallego y en portugués se llama también macela, marcela y magarza. Hay varias especies de manzanilla, pero a todas se les atribuyen las propiedades médicas mencionadas. A la especie llamada matricaria (Chrysanthemun parthenium) que recibe igualmente los nombres comunes de magarza, magarzuela y amagarza, pues se parece a la anterior, los griegos la llamaban Parthenion, que procede de la palabra parthenos; muchacha en estado de merecer o virgen, porque ya desde remotos tiempos, esta especie se emplea para socorrer a las mujeres jóvenes que necesitan regularizar los menstruos (Font Quer, 1976, 808-811). A la vulgar manzanilla o camomila se la llama también en Galicia Herba da Nosa Señora, y en Asturias se utiliza para hacer venir el menstruo o para normalizarlo (Junceda Avello, E., 1980, 287). En Francia se la conoce con el nombre de la madre de todas las

"CUADERNOS DE ESTUDIOS GALLEGOS", Tomo XLI, Fascículo 106, Santiago 1993-94. 
hierbas; se cree que favorece la concepción y se utiliza igualmente para la menstruación e incluso para evitar los abortos (Gélis, J., 1991, 29). En la Inglaterra de Shakespeare se creía en las propiedades regenerativas de la manzanilla; se decía popularmente que era una planta muy resistente y que cuanto más se la pisaba, más deprisa crecía:

The camomile, the more it is trodden on the faster it grows (Shak H. IV., II, 4, 389). Con estas breves referencias vemos que había una relación entre la magarcela y la fertilidad. Es muy probable también su empleo en las prácticas tradicionales tendentes a favorecer la concepción. Así, al menos, parece deducirse de la siguiente cántiga portuguesa:

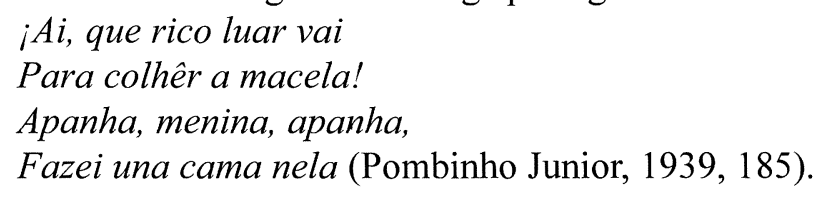

Por lo tanto, la inclusión del canto de alabanza a la magarcela en el canto do cabalo, es un testimonio popular de la existencia de una relación simbólica entre la fertilidad de los campos y la fecundidad de la mujer. Pero para ver con más claridad este análisis, es necesario que nos centremos más en algunos aspectos que aún no hemos visto.

Cuando concluían las faenas de la siega, los campesinos celebraban el día con ritos festivos no sólo porque la cosecha era el sustento para todo el invierno, sino también porque con sus tradiciones festivas pretendían asegurar para el próximo año la fertilidad de sus campos. En toda Europa se celebraban ritos parecidos. La creencia general que los vinculaba a todos era que ese mítico espíritu del campo se refugiaba en la última gavilla y que podía adoptar diversas formas de animal; de ahí viene el que esta gavilla tuviera distintos nombres, aunque había sorprendentes coincidencias. En los alrededores de Amiens, cuando se terminaba la recolección se decía que se iba a matar al gato, y cuando se segaba el último haz de cereal, mataban un gato. Esta costumbre es muy semejante a la que se realizaba en Carasa (Cantabria) el día de San Roque (16 de Agosto). Durante toda la tarde el pueblo entero se dedicaba a la captura de una gata negra; las casas, los tejados, las cuadras y los cobertizos eran rastreados con toda minuciosidad para localizar al felino, que necesariamente debía ser hembra y de pelaje negro. Mientras se realizaba la cacería, un grupo de jóvenes se disfrazaba con diversas prendas y se tiznaban sus rostros. Después adornaban un carro vistosamente con flores y enramados para transportar en él a la gata y al personaje designado oficialmente por tradición

"CUADERNOS DE ESTUdIOS GALLEGOS", Tomo XLI, Fascículo 106, Santiago 1993-94. 
popular para echar a la gata. Esta comitiva recorría las calles del pueblo entre risotadas, aspavientos y burlas festivas de los disfrazados, lo que daba a la fiesta un marcado tono carnavalesco. El recorrido finalizaba en la plaza y, después de la lectura de unas coplas burlescas, se echaba la gata negra sobre la concurrencia que emprendía tras ella una persecución simbólica con piedras y palos, prestándose especial atención a la dirección en que huía el animal. Si ésta se dirigía a la mies era presagio de fertilidad de los campos y buenas cosechas. Hubo ocasiones en que la pobre gata era cazada realmente y apaleada hasta la muerte. Después la enterraban en el campo con gran solemnidad (Montesino González, A., 1984, 49). En Casal de Cinza, en Guarda (Portugal) se hacía algo parecido con un gato que metían dentro de un cántaro amarrado a la punta de un palo y recubierto de paja. Cuando el fuego quemaba las cuerdas que ataban el cántaro, éste se caía y el gato huía despavorido perseguido por toda la chiquillería (Dias, J., 1951, 13).

En Alemania, uno de los nombres que se le daba a la última gavilla era el de la liebre y, al igual que en Suecia, Holanda, Francia e Italia, los campesinos proferían la misma expresión al segarla: ;Matar a la liebre!. Con ello se daba por concluida la cosecha. En Irlanda a esta acción se la denominaba sacar del campo a la liebre (Frazer, J.G., 1966, 280). Antes de proceder a segarla, los segadores irlandeses ataban bien la última gavilla en la que supuestamente se había ocultado la liebre. Solían competir entre ellos para ver quién era el segador más hábil. El procedimiento consistía en cortarla lanzando la hoz desde lejos, a veces con los ojos vendados. Al ganador se le regalaba un collar de pajas trenzadas. Cuando ganaba una mujer, se le pronosticaba su casamiento, pero al hombre se le decía que nunca se casaría. La gavilla cortada se la regalaban a la mujer del dueño de la tierra, que debía invitar a todos a una bebida. La gavilla se ponía casi siempre sobre la mesa de la comida que se celebraba ese día (Danaher, K., 1972, 191).

En Galloway (Escocia) a la última gavilla también la llamaban la liebre, y la cortaban al igual que en Irlanda lanzando la hoz desde lejos (Fenton, A., 1977). En el estudio de la distribución geográfica de los nombres de animales que se le daban a la última gavilla, nos encontramos con la siguiente clasificación por países:

BUEY: En Alemania, Francia y Suiza.

CABALLO: En Alemania, Francia (Norte), Galicia, Hertfordshire y en Shrospshire (Centro de Inglaterra) y en el País Vasco.

CABRA: En Alemania, Francia, Islas Hébridas, Noruega y Suiza.

"CUADERNOS DE ESTUDIOS GALLEGOS", Tomo XLI, Fascículo 106, Santiago 1993-94. 
CERDO: En Alemania, Dinamarca y Suecia.

CODORNIZ: En Austria, Normandía y Rumanía.

GALLO: En Alemania (Norte), Austria, Hungría, Picardía, Polonia, Rumanía.

GATO: En Alemania, Cantabria, Francia, Portugal (Norte), Polonia.

JABALÍ: En Alemania, Dinamarca, Suecia.

LIEBRE: En Alemania, Francia, Escocia, Holanda, Irlanda, Italia, Noruega, Portugal, Suecia y en el Valle del Aneo (Pirineo).

LOBO: En Alemania, Francia y países eslavos.

OVEJA: En Galicia y Portugal.

PERRO: En Alemania, Francia y países eslavos.

TORO: En Alemania, Francia y Suiza.

VACA: En Alemania, Francia y Suiza.

ZORRA: En Alemania, Francia, Galicia y Portugal.

Esta pequeña estadística pone de relieve el hecho de que en Alemania se utilizaban diversos nombres para referirse a la última gavilla, con la excepción de codorniz y oveja. Con respecto a Galicia, observamos que aquí se utilizaban tres nombres: caballo, oveja y zorra. Para Frazer esta disparidad de nombres de animales se debe a que a veces, cuando se efectuaban las labores de la siega, algún animal salvaje que se refugiaba en los trigales, se ocultaba tras las últimas gavillas al sentirse acorralado. Y en él se reencarnaba el espíritu del campo (Frazer, 1966, 270). De la misma opinión es Jorge Dias, para el cual a identicaçao do espirito do cereal com un estranho, em geral o própio dono da eirada, ou com um animal obedece ao mesmo processo psicológico. Para a mentalidade primitiva é fácil associar a súbita aparição de uma pessoa ou de um animal ao espirito do cereal, que liberto pela destruição do último feixe, onde se refugiara, vai encarnar ou habitar um ser vivo, homem ou animal 1951, 13). Por consiguiente, para los agricultores primitivos había una extraña asociación entre ese animal y el cereal. Cuando los sembrados carecían de cercas, cualquier animal podía ocultarse en ellos. Esto, según Frazer, determinó que los agricultores relacionaran también al espíritu del cereal con animales de gran tamaño, como toros o caballos, que no tenían impedimento alguno para introducirse en los cultivos. Los segadores imaginaron que dicho espíritu podía escaparse transformado en uno de esos animales. Para evitar que huyera, rodeaban la última gavilla y la cortaban siguiendo las pautas de esos ritos que hemos visto (Frazer, 1966, 304). Por eso los segadores de Santa Mara de Moreiras le cantaban a la última gavilla: 
Heiche de curtalas pernas as pernas che hei de curtar heiche de curtalas pernas pra que non poidas andar.

Heiche de curtalas pernas meu cabaliño, cabalo, heiche de curtalas pernas ¡Adiós, adiós, deica outro ano!

Hasta incluso la propia melodía de esta cantiga es de un enorme arcaismo. Su estructura es binaria, su línea melócida muy sencilla y termina na cláusula fundamental típica do alalá (De Dios Martínez, M., 1975, 216). El "Alala" es el canto gallego más elemental y primitivo de Galicia y pertenece a un fondo común indoeuropeo que pervive en diversas manifestaciones musicales del folklore (De Dios Martínez, op. cit.). O canto do cabalo entra, por lo tanto, dentro de la clasificación de las canciones lúgrubres de la siega (Fig. 1). Probablemente la más antigua sea el enirmático canto de Lelo vasco, en el que Caro Baroja ve la posible pervivencia de un canto tradicional al dios de un pueblo de agricultores, muerto en circunstancias trágicas y llorado o invocado en las poesías por aquellos:

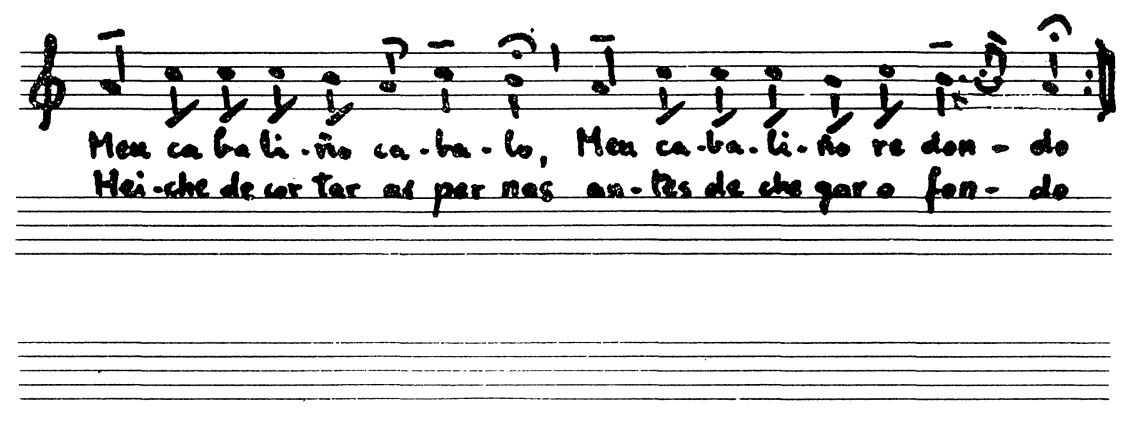

Figura 1.- La melodía del "Cabaliño" que se cantaba en la Límia alta (Ourense). (Según De Dios Martínez, M., 1975, 215).

"CUADERNOS DE ESTUDIOS GALLEGOS", Tomo XLI, Fascículo 106, Santiago 1993-94. 
Canción en la que, al parecer, un personaje llamado Lelo es muerto por Zara. Este canto se podría también comparar con el estribillo portugués:

Ai lari lari ló leló

Ai lari la ló meu bém (Caro Baroja, J., 1974, 93).

Con estos cánticos hay que relacionar los que cantaban los arrieros gallegos cuando guiaban los carros de bueyes por los caminos: el Ailelelo y su complementario Ailalala, constituían una tonada musical monótona y generalmente sin letra, que se cantaba muy pausadamente, prolongando las dos últimas sílabas: Ailaleeloo... Ailalaalaaa... Es un canto melancólico, como un quejido en el que se expresa una pena honda o un desencando íntimo. Pardo Bazán describe en una de sus obras su visión en Meirás (La Coruña) del paso de un carro de bueyes, delante del cual iba tirando de la cuerda y cantando uno de sus prolongadísimos ;Leé, lelo...lerelo lay! un mozo pelirrojo, en camisa y bragas de estopa, de pies descalzos, caminaba con no menor pereza y melancolía que sus bueyes, -como si no corriese gran prisa vivir (Pardo Bazán, 1888, 54).

Al comparar las tradiciones de la siega con las correspondientes de otros países, nos sorprendió ver que en Alemania, en el norte de Francia, en el centro de Inglaterra y en País Vasco también se llamaba caballo a la última gavilla. En el país de Gales, que linda con el condado de Shrospshire, le daban el nombre de yegua (Owen, T.M., 1991, 12). Tres posibles causas se me ocurren para explicar esta semejanza: La primera, lógicamente, que se trate de una pura coincidencia. Circunstancia en la que personalmente no creo. La segunda, que el empleo de ese término en este contexto llegó a Galicia con los germanos que introdujeron el mayal en la Península Ibérica. Por último, no podemos excluir, como decía más arriba, un origen anterior, lo que nos llevaría a los pueblos célticos o precélticos.

Cuenta Lorenzo Fernández en un artículo publicado en 1973, que en la parroquia de San Vicente de Lobeira, al SW de la provincia de Orense, llamaban raposa (zorra) a la última gavilla. Durante todo el año la guardaban en el pajar y, cuando llegaba la época de la siembra, la mezclaban con la simiente; lo que constituye un claro testimonio de la esperanza que se depositaba en el poder germinativo de la última gavilla. En ella se refugiaba el espíritu del campo bajo la supuesta forma de raposa (Lorenzo Fernández, X. 1973). Dice Lorenzo Fernández que en otros lugares de Galicia debió de existir también esta creencia, porque en Muros (La Coruña) se cantaba una cántiga que decía:

A raposa de Morrazo

"CUADERNOS DE ESTUdIOS GALLEGOS", Tomo XLI, Fascículo 106, Santiago 1993-94. 


\author{
velahí vai por entre o millo; \\ ela dí que nono come, \\ pero vaino chacudindo.
}

Es muy interesante esta referencia a la mítica raposa de Morrazo, animal fabuloso cuyos ladridos nocturnos dicen que atemorizaba a los habitantes de esa península de la provincia de Pontevedra, pues pronosticaban desgracias y muertes. En la península de Morrazo se creía que dicha raposa era un alma en pena que aparecía en cualquier esquina dando gritos tristísimos al mismo tiempo que salían de su boca ráfagas de fuego (Fraguas, A., 1969, 372). El zorro es un animal al que los pescadores de las Islas Británicas y de Galicia atribuyen diversas connotaciones negativas. Su nombre no se puede pronunciar nunca a bordo de las embarcaciones, pues se cree que basta con mencionarlo para que al instante ocurra algo desagradable. Su vinculación con la muerte, tanto en el área cultural británica, como en la gallega, es indicio de su origen común en las creencias de ultratumba célticas o germanas, cuyo reflejo lo vemos también en los tabúes lingüísticos que pesan sobre los nombres de otros animales (Alonso Romero, F., 1987). La ambivalencia de la raposa como animal de ultratumba y al mismo tiempo como representante del espíritu del grano, muestra perfectamente la estrecha unión que había entre las divinidades del otro mundo y las relacionadas con la fertilidad, de las que dependían los campos, el ganado y la vida humana (Rodríguez Álvarez, 1981, 80). Los pueblos agricultores primitivos mezclaban sus ritos de fertilidad con el culto a los muertos. En realidad, manifestaban con ello dos aspectos de una única religión: la manifestación de las esperanzas y de los temores de la comunidad (Rundle Clark, R.T., 1978, 119). Entre las divinidades del mundo clásico, Cibeles y Afrodita son dos buenos ejemplos de esta ambivalencia de atributos (Bergua, J.B., 1979, I, 118). En los antiguos mitos europeos las divinidades de la fertilidad telúrico-vegetal se convierten también en divinidades funerarias (Eliade, M., 1974, II, 131). Para Eliade es muy significativo el hecho de que las formas de animales bajo las que se manifiesta el espíritu de cereal, sean las mismas que suelen adoptar las almas de los muertos entre los germanos (Eliade, M., op. cit. 133). Para el campesino egipcio las almas de los muertos estaban siempre presentes en su vida cotidiana; cualquier cosa que sucediera, ya fuera buena o mala, en última instancia procedía de ellas (Rundle C., 1978, 119). Una visión muy parecida del devenir cotidiano se conserva todavía en muchas manifestaciones del alma popular gallega; la figura del antepa- 
sado, o del muerto, llega a concebirse como una existencia real que condiciona el comportamiento de los vivos.

Frazer menciona que en Alemania y en Francia también se creía que el espíritu del grano se encarnaba en un zorro; el zorro anda por los trigales, decían en Baviera cuando veían ondular las espigas con el viento (1966, I, 296). En Orense se decía: a volpe vai polo millo e nono come, mais dalle co rabo e sacode (Lorenzo Fernández, 1973, 350). Cuenta Lorenzo Fernández que antiguamente en Galicia también se debía de imaginar al espíritu del centeno con forma de lobo, porque él mismo recogió la creencia de que o lobo da malla vai no derradeiro feixe. El nombre de lobo se aplicaba en Alemania, en Francia y en los países eslavos a la última gavilla. En los viejos mitos europeos el lobo aparece relacionado con divinidades de ultratumba (Blázquez Martínez, J.M., 1958, 83).

Sería conveniente analizar detenidamente la relación que existe entre los animales que aparecen en las tradiciones de la siega y aquellos que figuran sacralizados en el panteón celta o en el germano. Esto podría mostrarnos una visión más completa que la que tenía Frazer, limitada únicamente a una explicación coherente pero insuficiente para aclarar las coincidencias que vemos. Tal tarea no se puede lógicamente abordar aquí pero queda esbozada para futuros trabajos. El folklore gallego sobre la agricultura es muy abundante y sobre él se han efectuado muy pocos estudios interpretativos. Ya los tiempos son otros, y esas creencias tradicionales han desaparecido o viven en el recuerdo borroso de algunos ancianos. Pero ahora que se habla tanto de una Europa común, no está de más recordar de donde venimos y que iguales somos a pesar de las lenguas o de otros episodios circunstanciales. Decía Jorge Dias que si encontramos no Norte de Portugal costumes tão semelhantes aos da Europa média e setentrional é porque eles devem ser anteriores á formaçao das nacionalidades europeias e provém de um fundo cultural comum, possivelmente difundido pelas migraçôes dos chamados povos célticos. Aunque fue en el Neolítico en donde se gestaron $(1951,14)$.

\section{BIBLIOGRAFÍA}

ALONSO ROMERO, F., 1987. Palabras tabú y eufemismos de los pescadores británicos: paralelos gallegos. (Coloquio Manuel Boaventura, 1985. Esposende, pp. 381-396). 
BERGUA, J.B., 1979. Mitología Universal. (Clásicos Bergua. Madrid).

BLÁZQUEZ MARTÍNEZ, J.M., 1958. La religiosidad de los pueblos hispanos vista por los autores griegos y latinos. (Emerita, vol. XXVI).

BOUZA BREY, F., 1953. Ritos agrarios propiciatorios del espiritu de la tierra de Galicia. (Revista de Dialectología y Tradiciones Populares, t. IX, 66-68).

BRAGA, T., 1985. O Povo Portugés nos seus costumes, crenças e tradiçoes. (Publicaçoes Dom Quixote, vol. I y II. Lisboa. $1^{\mathrm{a}}$ edición en 1885).

CABAL, C., 1958. Contribución al Diccionario Folklórico de Asturias. (Gráficas Summa. Oviedo).

CARO BAROJA, J., 1974. La significación del llamado canto de Lelo. (En: Algunos mitos españoles. Ediciones Centro. Madrid, pp. 93-117).

CONDE D'AURORA, 1966. Malhadas de centeio entre Douro e Minho. (Revista de Etnografía, vol. VII, t. I, pp. 25-54. Porto).

DANAHER, K., 1972. The Year in Ireland. (The Mercier Press. Cork).

DAVIDSON, H.E., 1993. The Lost Beliefs of Northern Europe. (Routledge. London).

DEANE, T. and SHAW, T., 1975. The Folklore of Cornwall. (B.T. Batsford Ltd. London).

DE DIOS MARTÍNEZ, M., 1975. O primitivismo do "alala". (Boletín Avriense, vol. V, pp. 207-217).

DEVLIN, J., 1987. The Superstitious Mind. (Yale University Press).

DIAS, J., 1951. Sacrificios simbólicos associados as malhas (Terra Lusa, $\mathrm{n}^{\circ}$ 1, pp. 5-15. Lisboa).

DOS SANTOS JUNIOR, J.R., 1963. Malha do centeio em Lavrada (Barroso). (Trabalhos de Antropología e Etnología, vol. XIX, fasc. I, pp. 47-68).

"CUADERNOS DE ESTUdIOS GALLEGOS", Tomo XLI, Fascículo 106, Santiago 1993-94. 
DOS SANTOS JUNIOR, J.R., 1964. O Grilo e a Raposa. (Trabalhos de Antropología e Etnología, vol. XIX, fasc. 3-4, pp. 374-376).

DOS SANTOS JUNIOR, J.R., 1977. A cultura dos cereais no leste trasmontano. (Trabalhos de Antropología e Etnología, vol. XXIII, fasc. I, pp. 41-159).

ELIADE, M. 1974. Tratado de Historia de las religiones. (Ediciones Cristiandad. Madrid.

FENTON, A., 1977. Scottish Country Life. (John Donald Publisher. Edinburgh).

FERNÁNDEZ OXEA, 1982. Santa Marta de Moreiras. (Ediciós do Castro. Sada).

FONT QUER, P., 1976. Plantas Medicinales. El Dioscórides renovado. (Labor. Madrid).

FRAGUAS, A., 1969. Algunos seres fantásticos de nuestra tierra. (Revista de Etnografía. Junta Distrital do Porto, vol. XII, t. 2, pp. 371377).

FRAZER, J.G., 1956. La Rama Dorada. (Fondo de Cultura Económica. México).

FRAZER, J.G., 1966. The Spirit of the Corn and the Wild. (En: The Golden Bough. MacMillan. London).

GELIS, J., 1991. History of Childbirth. (Polity Press. Cambridge).

HOLE, C., 1979. A Dictionary of British Folk Customs. (Granada Publishing. London).

JUNCEDA AVELLO, E., 1980. Etnología e Historia de la Ginecología en Asturias. (Arcano, Gijón).

KRAPPE, A.H., 1936. La Cailleach Bhéara. Notes de mythologie gaelique. (Etudes Celtiques, vol. I, pp. 292-302).

"CUADERNOS DE ESTUDIOS GALLEGOS", Tomo XLI, Fascículo 106, Santiago 1993-94. 
LISON TOLOSANA, 1979. Antropología Cultural de Galicia. (Akal. Madrid).

LORENZO FERNÁNDEZ, X., 1973. O esprito da mes en Lobeira. Ourense. (Cuadernos de Estudios Gallegos, vol. XXVIII, no 86, pp. 345-351).

MANDIANES CASTRO, M., 1984. Loureses. Antropología de una parroquia gallega. (Galaxia. Vigo).

MANNHARDT, W., 1884. Mythologische Forschungen (Estrasburgo).

MINGOTE CALDERÓN, J.L.,, 1988. Mayales y trillos en España. (Anales del Museo del Pueblo Español, vol. II, p. 83-169. Madrid).

MONTESINO GONZÁLEZ, A., 1984. Fiestas populares de Cantabria. (Ediciones Tantin. Santander).

O CRUALAOICH, G., 1988. Legends of Cailleach Bhéarra. (Bealoideas, vol. 56, pp. 153-178).

OHOGAIN, D., 1990. Myth, Legend \& Romance. (Ryan Publishing. London).

O'SULLIVAN, O., 1977. Legends from Ireland. (B.T. Batsford Ltd. London).

OWEN, T.M., 1991. Customs and Traditions of Wales. (Cardiff University of Wales Press).

PARDO BAZÁN, 1988. De mi tierra. (La Coruña).

POMBINHO JUNIOR, 1939. Retalhos de um vocabulario. (Revista Lusitana, vol. 37, pp. 153-270).

RISCO, V., 1947. Tradiciones referentes a algunos animales. (Revista de Dialectología y Tradiciones Populares, t. III, nº 3, 371-400).

"CUADERNOS DE ESTUDIOS GALLEGOS", Tomo XLI, Fascículo 106, Santiago 1993-94. 
RODRÍGUEZ ÁLVAREZ, 1981. Sincretismo de la religión indigena y la religión romana visto a través de las estelas antropomorfas. (Brigantium, vol. 2, pp. 73-82. Museo Arqueológico. La Coruña).

RODRÍGUEZ GONZÁLEZ, E., 1960. Diccionario Enciclopédico Gallego-Castellano. (Galaxia. Vigo).

RUNDLE CLARK, R.T., 1978. Myth and Symbol in Ancient Egypt. (Thames \& Hudson. London).

SHAKESPEARE, W. Henry IV.

TABOADA, J., 1965. La "malla" en' la comarca del Támega superior. (Trabalhos de Antropología e Etnología, vol. XX, fasc. 1-2, pp. 93118).

TENORIO, N., 1982. La aldea gallega. (Edicións Xerais de Galicia, $1^{\mathrm{a}}$ edición en 1914).

VEIGA DE OLIVEIRA et. al. 1983. Alfaia Agrícola Portuguesa. (Instituto Nacional de Investigaçao Científica. Lisboa).

WILDE, L., 1888. Ancient Legends Mystic Charms and Superstitions of Ireland ( $2^{\mathrm{a}}$ edición en 1971. O'Gorman Ltd. Galway).

"CUADERNOS DE ESTUdios GALLEGOS", Tomo XLI, Fascículo 106, Santiago 1993-94. 